\title{
Cell and Gene Therapies for Alzheimer's disease: a Review of Literature
}

\author{
*Afrânio Côgo Destefani ${ }^{1}$, Sousa FC $^{2}$ and Trabach GS ${ }^{2}$ \\ ${ }^{1}$ Professor of the Biomedicine Course of the Faculty of Biomedical Sciences of Espírito Santo, Brazil \\ ${ }^{2}$ Student of the Biomedicine Course of the Faculty of Biomedical Sciences of Espírito Santo, Brazil \\ Submission: January 21, 2017; Published: February 02, 2017
}

"Corresponding author: Afrânio Côgo Destefani, Professor of the Biomedicine Course of the Faculty of Biomedical Sciences of Espírito Santo, Cariacica/ES, Brazil, Rua Bolivar de Abreu, 48, Campo Grande, Cariacica/ES, ZIP CODE: 29.146-330, Email: afraniocd@gmail.com

\section{Abstract}

Alzheimer's disease (AD) is a progressive, high-cost neurodegenerative morbidity that promotes the deposition of beta-amyloid peptides $(\mathrm{A} \beta)$ and neurofibrillary tangles; there are neuronal loss affecting memory and intellectual abilities. Cellular Therapies (CT) and Gene Therapies (GT) have been studied for more effective treatments. CT consists of the application of undifferentiated cells, whereas TG utilizes viral vectors in the altered cell gene. We conducted a review of the literature, focusing on CT and GT. Through a bibliographical review we analyze publications between 2011 and 2015 (Figure 1). We observe that dementia diseases affect more than 47 million people, of which $60 \%$ are located in low and middle income countries; among dementias the AD corresponds to $60 \%$ of the cases. Strategies using immunotherapy with anti-A $\beta$ monoclonal antibody and adeno-associated viral vectors have demonstrated promising prospects in the treatment of disease in model mice and in human postmortem brains.

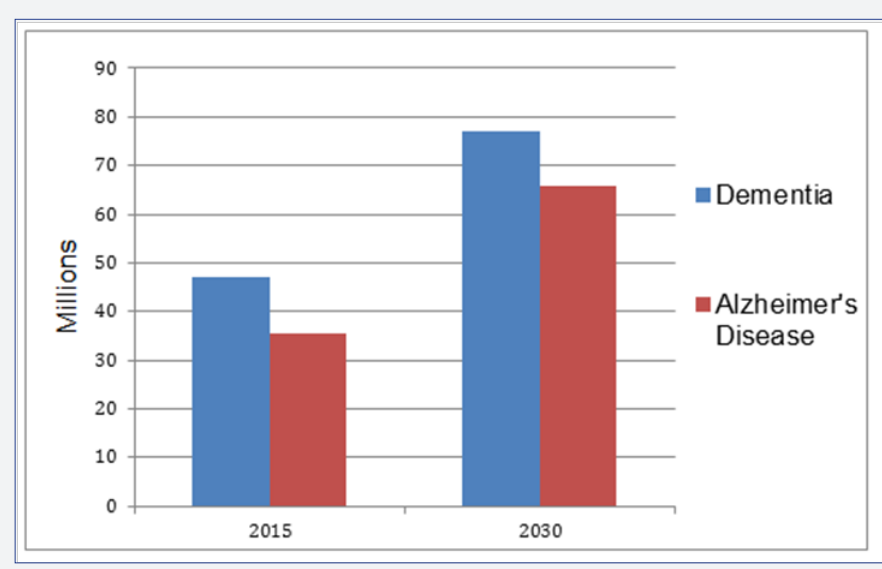

Figure 1: Comparison of epidemiological data on dementia with Alzheimer's disease in 2015 and 2030. Organización Mundial de laSalud (OMS) (2015) and Teixeira et al.

Keywords: Alzheimer's disease; Cell Therapy; Gene Therapy

Abbreviations: AD: Alzheimer's Disease; AB: Beta-Amyloid peptides; CT: Cellular Therapies; GT: Gene Therapies; p75NTR: Neurotrophin p75 Receptors; ESC: Embryonic Stem Cells; NGF: Nerve Growth Factor; AAV2: Adeno-Associated Virus 2; G-CSF: Granulocyte Colony Stimulating Factor; EEG: Electroencephalography; CSF: Cerebrospinal Fluid; MNB: Meynert Nucleus Basalis; CREB: CAMB Response Element Binding

\section{Introduction}

Dementia diseases affect more than 47 million people, of whom $60 \%$ are in low and middle income countries. Unfortunately, this number is expected to triple by population aging [1]. Among the dementias, Alzheimer's disease (AD) stands out, this corresponds to $60 \%$ of the cases. Currently there are approximately 35.6 million people with AD [2].
Considering the set of deaths due to diseases of the central nervous system in 2009, Alzheimer's disease represented $65 \%$ of deaths among women and $51.1 \%$ among men [2]. AD is the main cause of dementia, so far there is no clearly established therapy that reverses or normalizes the damage already done. In sporadic cases the pathological process is triggered by the deregulation of 


\section{Cancer Therapy \& Oncology International Journal}

neurotoxins and their receptors such as the precursor of nerve growth factor (proNGF) along with its receptors, sorption and neurotrophin p75 receptors (p75NTR) [3].

In animal studies it has been observed that it is possible to delay the progression of $\mathrm{AD}$ through cell therapy with the use of mesenchymal stem cells. These are able to differentiate into different tissue strains and can be obtained in the umbilical cord and the human bone marrow; however, it is an invasive and

difficult to perform method [4]. Concomitantly, gene therapy that uses gene identification and its introduction into plausible sites correlated with pathology can minimize the progression of $\mathrm{AD}$, thereby promoting reactivation of cell markers' functionality and signaling [5].

Alzheimer's disease is of particular importance because of the limitations it imposes on the patient, making pathological physiological changes of aging such as progressive loss of thinking and memorizing abilities, as well as affecting the brainrelated areas of language and behavior [6]. According to the Brazilian Association of Alzheimer's [7] the costs in relation to Alzheimer's disease are alarming and reverberate as a wave that affects society in all orders. One of the most effective ways of minimizing this effect is the early diagnosis of the disease, which requires the growing involvement of trained health professionals and with tooling for the procedure, both in the public network and in the private network.

Given its relative importance and the most recent methods for the treatment of $\mathrm{AD}$, it was proposed in this work to carry out a review of the literature focusing on cellular and gene therapies aiming to contribute to the diffusion of knowledge.

\section{Alzheimer's Disease Insight}

$\mathrm{AD}$ is a neurodegenerative disease, characterized by the presence of insoluble amyloid deposits, which may generate pro-inflammatory responses, thus impairing cellular functions of secretion and synapses. Age is the main risk factor for this pathology, but there are also genetic factors related to the APOE gene (Apolipoprotein E) [8]. Additionally, they reported that there is impairment of learning abilities, decreased language function leading to disorientation. This pathology presented in 2010 and 2011 the index of 35 million people affected in the world [9].

$\mathrm{AD}$ is characterized by a decrease in the cerebral metabolic rate of glucose utilization which can be installed in the individual in an early and progressive manner. The brain regions most affected are the prefrontal, temporal and parietal cortex, where $A \beta$ deposition occurs as well as cell atrophy. Such glucose declines are caused by cell loss that promotes decreased glucose utilization [10].

The incidence of $\mathrm{AD}$ progresses with increasing age this pathology is strictly related to the elderly age group. T-cell telomeres, which are correlated with the severity of the disease, are known to shorten because of their replicative history and cumulative oxidative stress exposure, so that protection against genomic instability no longer occurs. People with the APOE- $\varepsilon 4$ gene exhibit smaller leukocyte telomeres, which favors premature aging of the cell and may lead to cognitive decline and early mortality [11].

APOE- $\varepsilon 4$ is associated with increased $A \beta$ protein deposition along with phosphorylation of the tau protein, increasing the neurotoxic potential, leading to a reduction in brain cholinergic receptors. Such factors lead to the accumulation of senile plaques and the reduction of levels of choline acetyl transferase and acetyl cholinesterase [12].

\section{Cell Therapy}

Stem cells represent a group of undifferentiated cells capable of proliferating and self-renewing for long periods. In response to appropriate signals these cells can differentiate into mature and specialized cells. In humans, a large number of stem cells have already been identified and the same can be obtained from the embryo, fetus and adult individual. These are primarily found in the inner cell mass of early embryos, in some fetal tissues, in the umbilical cord and placenta, and in several adult organs and tissues, including the bone marrow. Embryonic stem cells (ESC) are pluripotent cells, they can originate cells from the three different germ layers of the embryo; Ectoderm, mesoderm and endoderm. When submitted in a cell culture environment, these cells proliferate indefinitely preserving their pluripotency. From the ESC, neuronal progenitors could be generated which would be able to differentiate into neurons, astrocytes and oligodendrocytes [13].

In animal studies they reported that it is possible to ameliorate the progression of $\mathrm{AD}$ by means of transplantation of mesenchymal stem cells, but this method is still invasive and difficult to perform. In this approach it is necessary to extract the stem cells in an appropriate amount, in a minimally invasive manner, and ensure appropriate means for cell survival. Stem cells can be transplanted into allogeneic or autologous hosts without immune rejection. Such procedures promote reduction of neuronal damage and promote support in the regeneration of injured nerves $[4,14]$.

It is important to note that transplants of human fetal midbrain tissue transplants for the treatment of Parkinson's disease were already addressed during the 1980s, but were confronted with a lack of and viability of donor cells and with Development of dyskinesia in patients. However, transplantation of mesencephalic human fetal tissue provided evidence of the principle that a cell replacement therapy could improve clinical symptoms in affected patients [13].

\section{Gene Therapy}

Gene therapy for $\mathrm{AD}$ has been proposed through the identification of genes that are related to the disease6. There have been reports of the use of nerve growth factor (NGF) 
in 10 patients with post-mortem $\mathrm{AD}$, and in two of them an improvement in the functionality and signaling of cellular markers was observed, and no adverse pathological effects were observed [15].

The application of gene therapy may occur through the use of viral vectors, due to the ability of the virus to infect the cell. Adeno-associated viruses and lent viruses are the most commonly used types [16]. Transgenic mice with high levels of beta-amyloid plaques, inadequate hippocampal function, and behavioral tests with deficits in associative and spatial memory had decreased c-FOS and BDNF genes (genes related to neurotransmission, synaptic plasticity, learning/memory and oxidative phosphorylation) targets of the CRTC-1 gene (Figure 2).

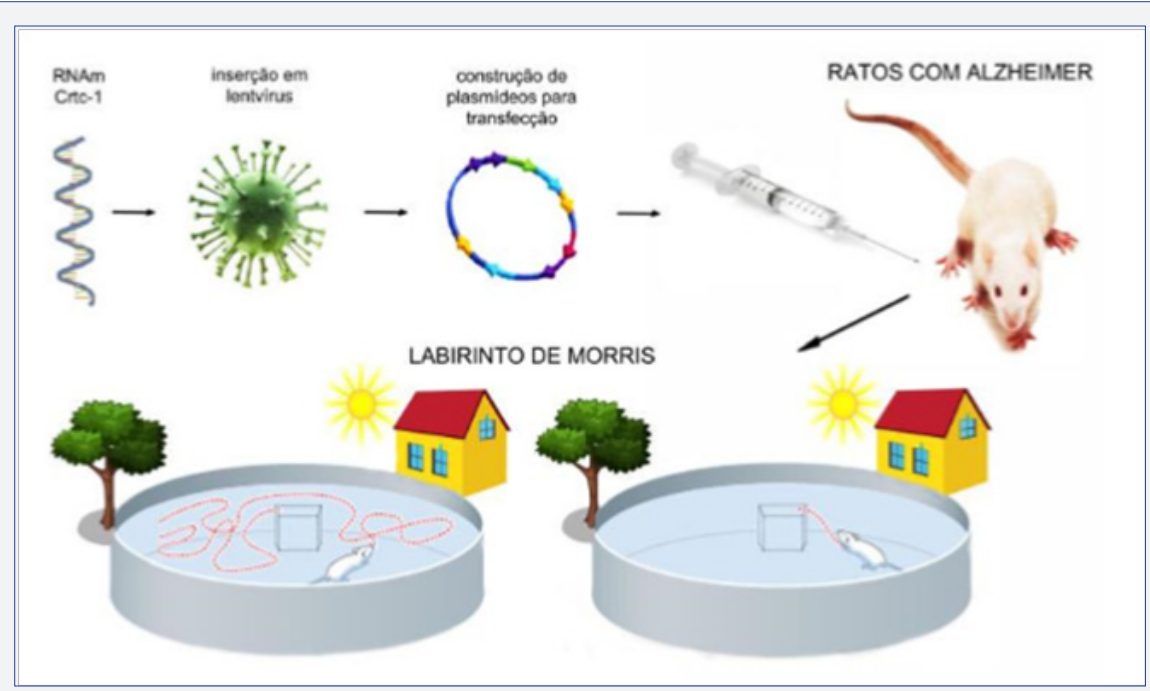

Figure 2: Overexpression of CRTC-1 in the hippocampus of Alzheimer's rats and Memory test. FURTADO CM, SANTOS DF, KIHARA AH, PASCHON V (2014).

Clinical trials were conducted in humans with neurodegenerative diseases which promoted a decrease in brain atrophy and improvement of memory and learning through the use of serotype adeno-associated virus 2 (AAV2) that facilitates the passage of the vector through the blood-brain barrier, can be used with NGF [16].

\section{CT/GT in AD Application's}

Of the references found through the descriptors used, 33 were analyzed, 26 of which were excluded through selective and analytical reading because they did not specifically address the themes "Cell and Gene Therapies for Alzheimer's Disease". Flowcharts 1 and 2 represent the sequential activities for the search and analysis of articles in PUBMED. Table 1 shows the quantitative and selected articles for the critical analysis totaling 7 articles

Table 1: Articles analyzed according to previously established criteria.

\begin{tabular}{|c|c|}
\hline Keywords & Pubmed \\
\hline $\begin{array}{c}\text { Alzheimer's Disease and Cell } \\
\text { Therapy }\end{array}$ & 5 \\
\hline $\begin{array}{c}\text { Alzheimer's Disease and Gene } \\
\text { Therapy }\end{array}$ & 2 \\
\hline Total & 7 \\
\hline
\end{tabular}

\section{Granulocitary colony stimulator factor (g-csf)}

Granulocyte colony stimulating factor (G-CSF) is a secreted hematopoietic cytokine responsible for the stimulation and mobilization of progenitor hematopoietic stem cells and that acts on the maturation of bone marrow-derived cells in neutrophilic granulocytes. G-CSF is widely used in the clinic for the treatment of chemotherapy-induced neutropenia and mobilizes progenitor stem cells in healthy donors for bone marrow transplantation. In this process there is mobilization of stem cells from the marrow into the blood, followed by their infiltration into the injured tissues, promoting auto repair by cellular Tran's differentiation of the marrow cells, differentiating into neurons, myocytes and other cellular phenotypes.

However, studies of female postmortem human brain samples that received bone marrow transplants of the opposite sex revealed that neurons and glia cells carried Y chromosomes. Thus, the current thinking is that cells derived from bone marrow Bone do not Trans differentiate in neural cells, but promote repair of the brain, releasing growth factors and immunomodulatory cytokines [17].

\section{Nerve growth factor (ngf)}

NGF demonstrated regenerative and neuro protective effects on cholinergic neurons of the basal forebrain in animal studies. Patients with AD treated with NGF showed improvement in cognition, improvement in EEG (electroencephalography) activity and glucose metabolism [18]. Preliminary results indicated a better clinical status and lower levels of A $31-42$ (peptide derived from a PPA through segmentation by the enzyme secretases) in cerebrospinal fluid (CSF). However, some patients 
showed greater brain atrophy and neuronal degeneration as evidenced by higher T-tau levels and CSF neurofilaments. Throughout the study, these patients presented lower cerebral atrophy and better progression in clinical variables and CSF biomarkers. These results support the idea that NGF may become a promising strategy for treatment for $\mathrm{AD}$ [18].

In 10 studied patients, all exhibited a trophic NGF response in the form of axonal budding. Comparing the treated and untreated sides of the brain in 3 patients who underwent unilateral gene transfer, cholinergic neuronal hypertrophy occurred on the side treated with NGF. Activation of cellular and functional signaling markers was present in 2 patients who were submitted to adeno-associated viral vectors mediated by NGF gene transfer. Neurons exhibiting tau pathology and tau-free neurons express the NGF, indicating that degenerative cells can be infected with therapeutic genes, with resulting activation of cell signaling There were no pathological adverse effects related to NGF [19].

\section{Active immunotherapy with $\mathbf{A} \beta$}

Many factors may cause $\mathrm{AD}$, but convergent evidence indicates a central role of aggregated $A \beta$ forms. Although the exact mechanism of toxicity of $A \beta$ is unknown, interventions that block aggregation and deposition of $A \beta$ are promising therapeutic options for $\mathrm{AD}$. Immunization and cleavage of the $\mathrm{A} \beta$ peptide may be an effective strategy in minimizing the progression of this pathology. Compared with passive immunotherapy, the active immunotherapy offers long-term advantages because there is continuous production and maturation of therapeutic antibodies in addition to a lower frequency of immunizations [20].

However, by employing a pharmaceutical form (AN1792 - Drug that induces reduction of beta-amyloid plaque) which contains synthetically produced $A \beta$, it was found that $6 \%$ of the patients exhibited meningoencephalitis. Therefore, this type of approach was stopped. Long-term follow-up studies confirmed that patients treated with AN1792 had a reduced response to antibodies. However, they exhibited a decline in caregiver dependence compared to patients treated with placebo, as well as a reduction in T-tau concentrations in CSF. These results indicate to some extent some of the potential benefits of active immunization in retarding disease progression [20].

\section{Immunotherapy with anti-A $\beta$ monoclonal antibody}

Treatment with Gantenerumab (anti-A $\beta$ monoclonal antibody) resulted in a dose-dependent reduction in the level of cerebral $\mathrm{A} \beta$ possibly through an effector cell-mediated mechanism [21].

In vivo (experiments with transgenic mice), Gantenerumab crossed the blood-brain barrier and specifically and reliably bound to APP (Amyloid Precursor Protein), proving that longterm treatment with Gantenerumab (more than five months) Significantly decreased the amyloid plaque load in the transgenic mice from the experiment [21]. The study also had 18 patients who demonstrated consistent changes in all regions where amyloid deposition was present except for the bridge, which is an area of the brain known to have limited $A \beta$ deposition.

Although reductions in amyloid levels were observed, treatment did not cause consistent effects on the cognition of the small group of patients treated for a short time with Gantenerumab [21]. The use of genes for performing AD treatments has the facility of being self-directed to the specific region to be treated using a safe viral vector that promotes the functional modification of the cells previously pathologically altered. This gene transfer provides biologically active protein in a controlled, predictable and lasting way safely and effectively [22].

\section{Vector vectors}

The viral vector (AAV2-ATCC VR-1616 - which exhibits high ability to infect the population without causing damage to normal cells) is implanted in the basal forebrain and induces the production and secretion of NGF. Such location is of paramount importance because there are cholinergic cells that send information to the entire cortex and hippocampus, promoting the maintenance of cognitive functions. In vivo studies the neuronal accumulation of NGF was more intense in the neurons adjacent to the insertion sites compared to neurons with more distant location. In the ex vivo experiments, after the application of NGF, growth of cholinergic axons was observed towards the insertion point of the genes denoting activation of the gene within 10 years after the treatment. In this type of application were not seen nonspecific effects in relation to the NGF target, either any identification of tumor formation or evidence of neuronal toxicity [19].

\section{Aden-Associated Viral vectors (AAV)}

It consisted of the application of the gene in Meynert nucleus basalis (MNB). This location was chosen because it is a source of cholinergic neurons input to the neocortex and has a large amount of cholinergic receptors. Differently from 20, NGF expression persisted for at least 4 years after gene application and induced responses of neurotrophic hypertrophy in NBM neurons that were exposed to NGF protein [22].

As in the case of the transfer of the NGF gene, which obtained the activation of the c-FOS gene and CREB (Protein that acts as transcription factor - CAMB Response Element Binding) in 2 patients, who underwent transfer of AAV2-NGF viral vectors in NBM? Such a vector also inoculates into neurons that express tau pathology [19].

The safety and tolerability of the application of stereotactic injections (minimally invasive surgical intervention using threedimensional coordinates) of the AAV2-NGF vector dose and chronic expression of NGF were shown to be viable, safe and well tolerated in patients with mild and moderate AD. The results of adverse effects $76 \%$ were mild, $21 \%$ moderate and $4 \%$ severe, which had as it's only case the hypertension of a patient $[22,23]$. 


\section{Cancer Therapy \& Oncology International Journal}

\section{Perspectives of the therapies addressed}

Research on $\mathrm{AD}$ therapy was able to develop for symptomatic relief - at least partially effective, but failed in terms of disease progression stalling. Drugs approved for the treatment of AD are limited to acetyl cholinesterase (donepezil, rivastagmine, galantamine) or NMDA receptor antagonists (memantine).They potentially improve cognition, behavior and overall clinical status, but their efficacy is very limited. Among the drugs modifying the general disease picture that have been evaluated to date, the most numerous tests are passive immunosuppression.

Results from animal studies have shown that anti-A $\beta$ antibodies can prevent oligomer formation and reduce cerebral amyloid burden by improving cognitive functions. Several monoclonal antibodies are currently being tested. However, early clinical trials have been disappointing, leading to the initiation of clinical trials in which treatment is initiated in pre-symptomatic patients or in patients at a very early stage of the disease. There is still a great unmet need to identify therapies with the potential to slow disease progression and improve cognitive function in patients with AD.

Concomitantly, cell replacement therapies have great potential for the treatment of patients with $\mathrm{AD}$. With the advent of technologies related to the use of stem cells and the ability to transform stem cells into different types of neurons of the central nervous system and into glial cells, advances in cell therapy were glimpsed in animal models for AD. Although these preclinical studies are promising, many gaps remain open with regard to the processes of the application of stem cell therapies. These gaps are listed as the key point for the success of this type of approach in patients with AD.

\section{Materials and Methods}

The research used was a bibliographical review; having as basis the data indexed works in the US National Library of Medicine National Institutes of Health (PubMed), available at https://www.ncbi.nlm.nih.gov/pubmed/. Key words: "Alzheimer's Disease AND Cell Therapy" and "Alzheimer's Disease AND Gene Therapy" were used. It was considered work published in the last 5 years (2011 - 2015) and that were classified as experimental (Clinical Trial) (Figures 3 \& 4).

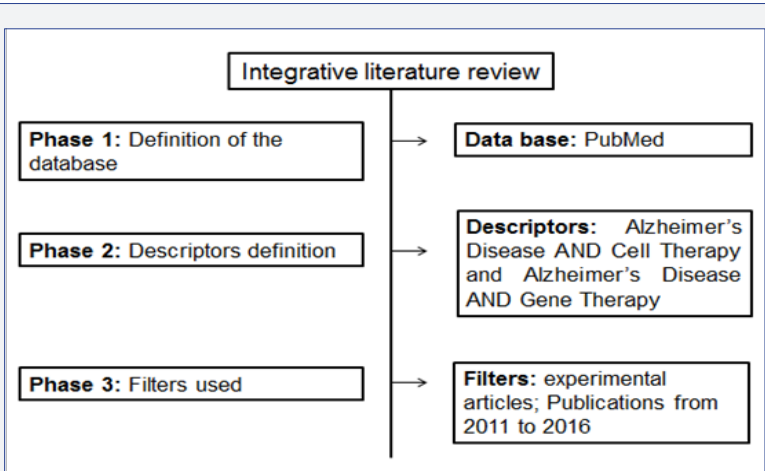

Figure 3: Phases for the realization of the material and meth-

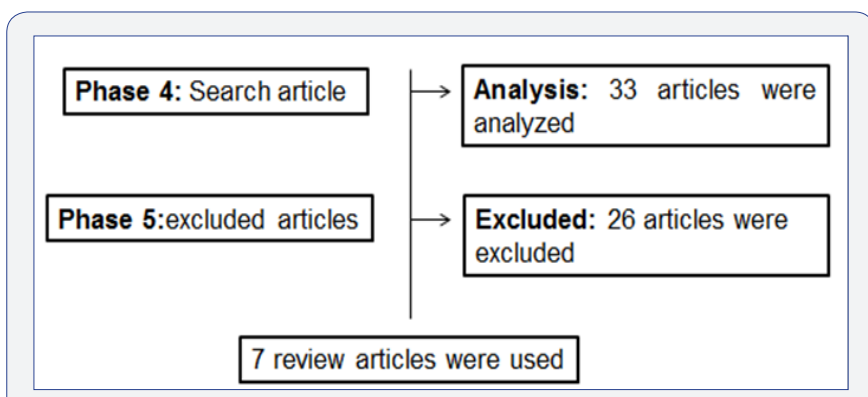

Figure 4: Activities used to search for articles in PubMed.

\section{Research in Context}

Considering the set of deaths due to diseases of the central nervous system in 2009, Alzheimer's disease represented 65\% of deaths among women and $51.1 \%$ among men. AD is the main cause of dementia, so far there is no clearly established therapy that reverses or normalizes the damage already done. AD is of particular importance because of the limitations it imposes on the patient, making pathological physiological changes of aging such as progressive loss of thinking and memorizing abilities, as well as affecting the brain-related areas of language and behavior.

One of the most effective ways of minimizing this effect is the early diagnosis of the disease, which requires the growing involvement of trained health professionals and with tooling for the procedure, both in the public network and in the private network. Given its relative importance and the most recent methods for the treatment of AD, it was proposed in this work to carry out a review of the literature focusing on cellular and gene therapies aiming to contribute to the diffusion of knowledge.

Cell replacement therapies have great potential for the treatment of patients with AD. With the advent of technologies related to the use of stem cells and the ability to transform stem cells into different types of neurons of the central nervous system and into glial cells, advances in cell therapy were glimpsed in animal models for AD. Although these preclinical studies are promising, many gaps remain open with regard to the processes of the application of stem cell therapies. These gaps are listed as the key point for the success of this type of approach in patients with $\mathrm{AD}$

\section{References}

1. Organización Mundial de la Salud (OMS) (2015) Los gobiernos se comprometen a impulsar la investigación y atención de la demência.

2. Jane Blanco Teixeira, Paulo Roberto Borges de Souza, Joelma Higa, Mariza Miranda Theme Filha (2015) Doença de Alzheimer: estudo da mortalidade no Brasil, 2000-2009. Cad. Saúde Pública 31(4).

3. Yao XQ, Jiao SS, Saadipour K, Zeng F, Wang QH, et al. (2015) p75NTR ectodomain is a physiological neuroprotective molecule against amyloid-beta toxicity in the brain of Alzheimer's disease. Mol Psychiatry 20(11): 1301-1310.

4. Hongna Yang, Hui Yang, Zhaohong Xie, Lifei Wei, Jianzhong Bi (2013) Systemic Transplantation of Human Umbilical Cord Derived 


\section{Cancer Therapy \& Oncology International Journal}

Mesenchymal Stem Cells-Educated T Regulatory Cells Improved the Impaired Cognition in AßPPswe/PS1dE9 Transgenic Mice. PLoS One 8(7): e69129.

5. Kevin D Fowler, Jason M Funt, Maxim N Artyomov, Benjamin Zeskind, Sarah E Kolitz, et al. (2015) Leveraging existing data sets to generate new insights into Alzheimer's disease biology in specific patient subsets. Scientific Reports 14324.

6. Ferreira LL, Cochito CT, Caíres F, Marcondes PL, Saad BCP (2014) Capacidade funcional de idosos institucionalizados com e sem doença de Alzheimer. Rev Bras Geriatr Gerontol 17(3): 567-573.

7. Associação Brasileira de Alzheimer (ABRAz) (2012). DOENÇA DE ALZHEIMER.

8. Joe M Butler, Umar Sharif, Manir Ali, Martin McKibbin, Joseph P, et al. (2015) A missense variant in CST3 exerts a recessive effect on susceptibility to age-related macular degeneration resembling its association with Alzheimer's disease. Hum Genet 134(7): 705-715.

9. Georgievska B, Sandin J, Doherty J, Mörtberg A, Neelissen J, et al. (2013) AZD1080, a novel GSK3 inhibitor, rescues synaptic plasticity deficits in rodent brain and exhibits peripheral target engagement in humans. J Neurochem 125(3): 446-456

10. Samuel T Henderson, Judes Poirier (2011) Pharmacogenetic analysis of the effects of polymorphisms in APOE, IDE and IL1B on a ketone body based therapeutic on cognition in mild to moderate Alzheimer's disease; a randomized, double-blind, placebo-controlled study. BMC Med Genet 12: 137.

11. Jacobs EG, Kroenke C, Lin J, Epel ES, Kenna HA, et al. (2013) Accelerated Cell Aging in Female APOE- $\varepsilon 4$ Carriers: Implications for Hormone Therapy Use. PLoS One 8(2): e54713.

12. Han HJ, Kim BC, Lee JY, Ryu SH, Na HR, et al. (2012) Response to rivastigmine transdermal patch or memantine plus rivastigmine patch is affected by apolipoprotein E genotype in Alzheimer patients. Dement Geriatr Cogn Disord 34(3-4): 167-173.

13. Abdel-Salam OM (2011) Stem cell therapy for Alzheimer's disease. CNS Neurol Disord Drug Targets 10(4): 459-485.

This work is licensed under Creative

Commons Attribution 4.0 License

DOI: 10.19080/CTOIJ.2017.03.555603
14. Kim S, Chang KA, Kim Ja, Park HG, Ra JC, et al. (2012) The Preventive and Therapeutic Effects of Intravenous Human Adipose-Derived Stem Cells in Alzheimer's Disease Mice. PLoS One 7(9): e45757.

15. Tuszynski MH, Yang JH, Barba D, U HS, Bakay RA, et al. (2015) Nerve Growth Factor Gene TherapyActivation of Neuronal Responses in Alzheimer Disease. JAMA Neurol 72(10): 1139-1147.

16. O'Connor DM, Boulis NM (2015) Gene therapy for neurodegenerative diseases. Trends Mol Med 21(8): 504-512.

17. Sanchez-Ramos J, Cimino C, Avila R, Rowe A, Chen R, et al. (2012) Pilot Study of Granulocyte-Colony Stimulating Factor for Treatment of Alzheimer's disease. J Alzheimer's Dis 31(4): 843-855

18. Ferreira D, Westman E, Eyjolfsdottir $H$, Almqvist $P$, Lind $G$, et al. (2015) Brain changes in Alzheimer's disease patients with implanted encapsulated cells releasing nerve growth factor. J Alzheimers Dis 43(3): 1059-1072.

19. Tuszynski MH, Yang JH, Barba D, U HS, Bakay RA, et al. (2015) Nerve Growth Factor Gene Therapy Activation of Neuronal Responses in Alzheimer Disease. JAMA Neurology 72(10): 1139-1147.

20. Winblad B, Andreasen N, Minthon L, Floesser A, Imbert G, et al. (2012) Safety, tolerability, and antibody response of active $A \beta$ immunotherapy with CAD106 in patients with Alzheimer's disease: randomized, double-blind, placebo-controlled, first-in-human study. Lancet Neurol 11(7): 597-604.

21. Ostrowitzki S, Deptula D, Thurfjell L, Barkhof F, Bohrmann B, et al. (2011) Mechanism of amyloid removal in patients with Alzheimer disease treated with gantenerumab. Arch Neurol 69(2): 198-207.

22. Rafii MS, Baumann TL, Bakay RA, Ostrove JM, Siffert J, et al. (2014) A phase1 study of stereotactic gene delivery of AAV2-NGF for Alzheimer's disease. Alzheimers Dement 10(5): 571-581.

23. Cristina Moreira Furtado, Diego Félix dos Santos, Alexandre Hiroaki Kihara, Vera Paschon (2014) Terapia Gênica Recupera MEmória De Ratos Com Alzheimer: um novo passo em direção à cura. Nanocell New 1(11): 13.

\section{Your next submission with Juniper Publishers} will reach you the below assets

- Quality Editorial service

- Swift Peer Review

- Reprints availability

- E-prints Service

- Manuscript Podcast for convenient understanding

- Global attainment for your research

- Manuscript accessibility in different formats

( Pdf, E-pub, Full Text, Audio)

- Unceasing customer service

Track the below URL for one-step submission https://juniperpublishers.com/online-submission.php 